\title{
Reduction of Tropical Cloudiness by Soot
}

A.S. Ackerman, O.B. Toon, D.E. Stevens, A.J. Heymsfield, V. Ramanathan and E.J. Welton

\section{U.S. Department of Energy}

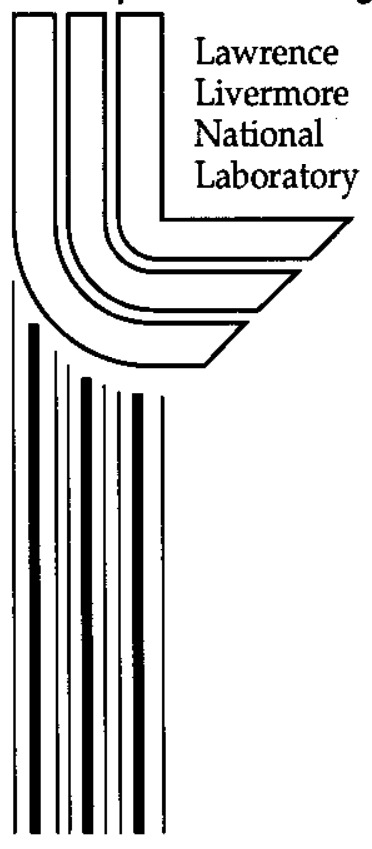

May 8, 2000 


\section{DISCLAIMER}

This document was prepared as an account of work sponsored by an agency of the United States Government. Neither the United States Government nor the University of California nor any of their employees, makes any warranty, express or implied, or assumes any legal liability or responsibility for the accuracy, completeness, or usefulness of any information, apparatus, product, or process disclosed, or represents that its use would not infringe privately owned rights. Reference herein to any specific commercial product, process, or service by trade name, trademark, manufacturer, or otherwise, does not necessarily constitute or imply its endorsement, recommendation, or favoring by the United States Government or the University of California. The views and opinions of authors expressed herein do not necessarily state or reflect those of the United States Government or the University of California, and shall not be used for advertising or product endorsement purposes.

Work performed under the auspices of the U.S. Department of Energy by the University of California Lawrence Livermore National Laboratory under Contract W-7405-Eng-48.

This report has been reproduced directly from the best available copy.

Available to DOE and DOE contractors from the Office of Scientific and Technical Information

P.O. Box 62, Oak Ridge, TN 37831

Prices available from (423) 576-8401

http://apollo.osti.gov/bridge/

Available to the public from the National Technical Information Service

U.S. Department of Commerce 5285 Port Royal Rd., Springfield, VA 22161 http://www.ntis.gov/

OR

Lawrence Livermore National Laboratory Technical Information Department's Digital Library http://www.llnl.gov/tid/Library.html 


\title{
Reduction of tropical cloudiness by soot
}

\author{
A. S. Ackerman ${ }^{*}$, O. B. Toon ${ }^{2}$, D. E. Stevens ${ }^{3}$, A. J. Heymsfield ${ }^{4}$, V. Ramanathan 5 , \\ E. J. Welton 6
}

Measurements and models show that enhanced aerosol concentrations can augment cloud albedo not only by increasing total droplet cross-sectional area, but also by reducing precipitation and thereby increasing cloud water content and cloud coverage. Aerosol pollution is expected to exert a net cooling influence on the global climate through these conventional mechanisms. Here we demonstrate an opposite mechanism through which aerosols can reduce cloud cover and thus significantly offset aerosol-induced radiative cooling at the top of the atmosphere on a regional scale. In model simulations the daytime clearing of trade cumulus is hastened and intensified by solar heating in dark haze (as found over much of the northern Indian Ocean during the northeast monsoon).

1NASA Ames Research Center, Moffett Field, CA, 94035, USA.

2 University of Colorado, Boulder, CO, 80309, USA.

3 Lawrence Livermore National Laboratory, Livermore, CA, 94551, USA.

4National Center for Atmospheric Research, Boulder, CO, 80301, USA.

5 Scripps Institution of Oceanography, La Jolla, CA, 92093, USA.

${ }^{6}$ Science Systems and Applications, Greenbelt, MD, 20771, USA.

*To whom correspondence should be addressed. E-mail: ack@sky.arc.nasa.gov 
A primary objective of the Indian Ocean Experiment (INDOEX) was to quantify the indirect effect of aerosols on climate through their effects on clouds (1). Conventionally, increased aerosol concentrations are expected to increase cloud droplet concentrations, and hence total droplet cross-sectional area, thereby causing more sunlight to be reflected to space (2). Furthermore, model simulations of marine stratocumulus $(3,4,5)$ and observations of ship tracks $(6,7,8)$ suggest that increased aerosol concentrations can enhance cloud water content, physical thickness and areal coverage by decreasing precipitation. Deep layers of dark (solar absorbing) haze were observed over much of the tropical northern Indian Ocean in February-March of 1998-1999 during INDOEX $(9,10)$. The clouds observed in the northern hemisphere were typically embedded in the haze, as seen in Fig. 1. In contrast to the conventional expectation that aerosols augment cloud depth and coverage, very sparse cloud cover is found in that region during that time of year (11). These INDOEX observations suggest a new mechanism by which aerosols impact clouds, in which a dark haze can significantly reduce areal coverage of trade cumulus (the predominant cloud type expected at that latitude and season).

Model simulations of marine stratocumulus indicate that intense absorption of solar energy can desiccate an optically thick stratocumulus cloud layer (12). Here we show that significantly less intense aerosol-induced solar absorption, of the magnitude observed in the 1998 INDOEX measurements, can drastically alter the properties of trade cumulus, which are driven by dynamics that differ greatly from stratocumulus (13). In well-mixed stratocumulus-topped boundary layers found over cool subtropical water, convection is driven by downdrafts that are generated by radiative cooling near cloud top. Enhanced solar heating can offset the longwave cooling enough to reduce convective mixing and effectively cut off the cloud layer from its source of moisture, thereby dissipating the cloud (12). Trade-cumulus are found over warm tropical water in boundary layers typically $\sim 1.5-3 \mathrm{~km}$ deep (compared to less than $\sim 1 \mathrm{~km}$ for stratocumulus-topped mixed layers) and appear in the conditionally unstable zone between the well-mixed surface layer and the trade inversion capping the boundary layer. In the trade-wind boundary layer, particularly energetic updrafts rise far enough and release enough latent heat by condensation to become buoyant, accelerating upwards until resisted by the stability of the trade inversion. Detrained cloud water spreads out below the trade inversion as an anvil, evaporating as it mixes with its environment. Trade-cumulus cloud cover is typically dominated by these remnants of convection, which evaporate more rapidly with decreasing humidity (14). Infrared cooling from anvils can drive local turbulence, which mixes moisture up from below $(\underline{13}, 15)$. 
The INDOEX observations suggest a conceptual model in which dark haze amplifies the radiatively-driven diurnal cycle of cloudiness by increasing solar heating in the boundary layer. Composited time series of cloud coverage from trade-cumulus field projects all show sinusoidal variation, with maximum coverage between 7 and $10 \mathrm{AM}$, and a minimum between 4 and 10 PM (10). The daytime clearing has been attributed to two complementary mechanisms: (i) solar heating directly reduces relative humidities, thereby accelerating evaporation of the anvils, and (ii) solar heating maximizes near the top of the boundary layer, where cloud coverage is greatest, thereby stabilizing the boundary layer and suppressing convection (10).

We focus here on the amplification of daytime clearing due to aerosol-induced solar heating. Rather than attempting to cover the many possible combinations of meteorology and pollution, our strategy is to adopt a representative trade-cumulus scenario and compare a sequence of model simulations subject to varying degrees of aerosol-induced solar heating. The tool we use is a large-eddy simulation model (17) with parameterized precipitation $(\underline{13})$ and plane-parallel radiative transfer $(18)$.

For a meteorological context we use measurements averaged over the first five days of the Atlantic Trade-Wind Experiment (ATEX), characterized as "nearly classic" trade-cumulus (19). The model is initialized with surface conditions and soundings from the upstream ship in the ATEX flotilla (20). As in previous studies $(\underline{14}, \underline{15}, \underline{16})$, we ignore any diurnal variation in sea-surface temperature (21). Large-scale advective forcings are parameterized to represent the net influx of cooler, drier air in the equatorward flow through the model domain (22).

We specify varying degrees of absorbing aerosol pollution as follows (23). For the baseline case, cloud droplet and haze concentrations are fixed at 250 and $1200 \mathrm{~cm}^{-3}$, respectively (24); in this case the haze is non-absorbing and has an optical depth of 0.17 (at $0.5 \mu \mathrm{m}$ ). We idealize the 1998 INDOEX measurements with the same concentrations, embedding a soot core of $0.06 \mu \mathrm{m}$ radius within each haze particle and resulting in a $0.5-\mu \mathrm{m}$ single-scattering albedo of 0.88 and optical depth of 0.20 . The aerosol-induced diurnal-average solar heating of the cloudless boundary layer for this haze is $0.5 \mathrm{~K} / \mathrm{d}(25)$. We idealize the more polluted conditions measured during the 1999 INDOEX campaign by doubling the concentration of haze particles, which all have soot cores.

Fig. 2 reveals a number of salient features of the baseline simulations (26). Cumulus convection, with cloud-base atop the surface mixed-layer, arises an hour into the simulation and penetrates the $250 \mathrm{~m}$ deep trade-inversion starting at $\sim 1600 \mathrm{~m}$. Subsequent convection is sporadic, owing to our limited model domain $(6.4 \times 6.4 \mathrm{~km})$. A local maximum of relative 
humidity persists at cloud base, and a greater maximum associated with stratiform anvils persists just below the trade inversion. Corresponding peaks in diurnal-average cloud fractions are $2 \%$ at cloud base and $\sim 15 \%$ in the stratiform anvil (27). Representative snapshots of the simulated cloud field shown in Fig. 3 qualitatively resemble the observed clouds shown in Fig. 1. Solar heating reduces relative humidities in the cloud layer through late afternoon (the sun rises at $6 \mathrm{~h}$ and sets at $18 \mathrm{~h}$ ). After sunset, stronger convection episodically dries the boundary layer through penetrative entrainment of inversion air. The diurnal variation is more evident in the domain-average fractional cloud-coverage (Fig. 4A), generally matching the characteristic diurnal cycle observed $(\underline{16}, 28)$. The liquid water path (Fig. 4B) follows a similar tendency, leveling off from model spin-up in the morning, decreasing through the day, and recovering in the evening. To show that the diurnal variations are driven by insolation, a simulation identical to the baseline except lacking solar radiation displays no daytime clearing (Figs. 4A and B).

Incorporating an absorbing component (soot) into the haze enhances the solar heating of the boundary layer, increasing temperatures and thereby lowering relative humidities and abbreviating anvil lifetimes. As shown in Figs. 4A and B, aerosol-induced solar absorption in the INDOEX 1998 haze amplifies the daytime reductions in cloud coverage and liquid water path relative to the baseline (29). For the murkier INDOEX 1999 haze, the reductions are further intensified and persist well into night. The boundary layer also becomes shallower in response to solar heating (Fig. 4C), as boundary-layer mixing is less able to offset subsidence of the inversion (the average daytime turbulent kinetic energy above the surface layer decreases by $\sim 30$ and 50\% relative to the baseline for the INDOEX 1998 and 1999 cases, respectively). Averaged over daytime (Fig. 5A), the INDOEX 1998 and 1999 hazes reduce fractional cloud coverage by 25 and $40 \%$ (relative to the baseline ensemble median of 0.19 ).

To investigate the sensitivity of our results to variations in cloud microphysics, we run further simulations that span the range of droplet concentrations measured during INDOEX, at 50,100 , and $500 \mathrm{~cm}^{-3}$. Differencing the curves in Fig. $5 \mathrm{~A}$, it is seen that the reduction of cloud coverage due to the cloud-burning effect of soot is roughly constant over the range of droplet concentrations (30). For all three hazes, conventional indirect effects result in daytime cloud coverage increasing with droplet concentrations (31). The conventional indirect effects of aerosols on cloud coverage oppose the cloud-burning effect of soot. Hence, aerosol pollution may increase or decrease cloud coverage; the net effect depends on meteorological conditions (32) and the concentrations and optical properties of cloud droplets and haze in the unpolluted and unpolluted clouds. For example, if the droplet concentration in unpolluted clouds (without 
soot) is $100 \mathrm{~cm}^{-3}$ (open circle in Fig. 5A) and pollution increases the droplet concentration to $250 \mathrm{~cm}^{-3}$, then for the INDOEX 1999 haze (closed circle) the daytime cloud coverage decreases from an unpolluted value of 0.18 to a polluted value of 0.11 . For unpolluted droplet concentrations $\geq 100 \mathrm{~cm}^{-3}$, no amount of increase in droplet concentrations completely offsets the reduction in cloud coverage for the INDOEX 1998 haze in these simulations. For the INDOEX 1999 haze no offsetting balance occurs, even starting with an unpolluted droplet concentration of $50 \mathrm{~cm}^{-3}$.

Reductions in cloud coverage due to aerosol-induced solar absorption strongly effect the radiative heat budget at the surface and top-of-atmosphere (TOA) on a regional scale (33). However, aerosols exert other radiative forcings: directly through absorption and scattering, and indirectly through increasing cloud droplet concentrations. To contrast the components of aerosol forcing, we next compare net forcings under clear and cloudy conditions by progressively adding aerosol forcings (Table 1).

The cloudy and clear-sky radiative effects of only the soot in the INDOEX 1998 haze are shown in the first line of Table 1. Under clear skies the soot exerts a small radiative forcing of $+0.4 \mathrm{~W} / \mathrm{m}^{2}$ (the indistinguishable difference between solid and dotted lines at a droplet concentration of zero in Fig. 5C). With clouds to burn (at a droplet concentration of $250 \mathrm{~cm}^{-3}$ ) the radiative forcing of soot is amplified by nearly a factor of ten, to more than twice the global-average forcing estimated for atmospheric $\mathrm{CO}_{2}$ increase since preindustrial times (34).

Net radiative forcings due to aerosol absorption and scattering combined are shown in the second line of Table 1 (note that the difference between the INDOEX 1998 and 1999 hazes is equivalent to the difference between no haze and the INDOEX 1998 haze; hereafter we refer to this difference as the "INDOEX 1998 haze equivalent"). Under clear skies the INDOEX 1998 haze equivalent exerts a net TOA cooling, but under cloudy skies (at droplet concentrations $\geq 100$ $\mathrm{cm}^{-3}$ ), the cooling is completely offset by cloud-burning. The net TOA warming (the difference between the dotted and dashed curves in Fig. 5C) increases with the amount of cloud available to burn. Doubling the extinction in the haze equivalent, the aerosol forcing is $+4.5 \mathrm{~W} / \mathrm{m}^{2}$ (the difference between the solid and dashed curves in Fig. 5C at a droplet concentration of 250 $\mathrm{cm}^{-3}$ ). Hence, relative to the clear-sky forcing of $-3.0 \mathrm{~W} / \mathrm{m}^{2}$, the cloud-burning effect increases the net aerosol forcing by $+7.5 \mathrm{~W} / \mathrm{m}^{2}$.

Including the conventional indirect aerosol forcings requires an assumption regarding changes in cloud droplet concentrations. Because it is difficult if not imposible to estimate the droplet concentrations for pristine continental outflow from India, we loosely base our choice of 
droplet concentrations for unpolluted and polluted conditions (at 100 and $250 \mathrm{~cm}^{-3}$, respectively) on hemispheric differences measured during INDOEX. As seen in Fig. 5B, the average liquid water path (which incorporates cloud coverage effects) is largely independent of droplet concentration for simulations with a particular haze. However, holding liquid water constant while increasing the droplet concentration from 100 to $250 \mathrm{~cm}^{-3}$ increases cloud optical depth by a factor of $(250 / 100)^{1 / 3} \approx 1.4$, which increases cloud albedo and tilts the balance back to a net radiative cooling for the INDOEX 1998 haze equivalent (compare the second and third lines of Table 1). In this case the magnitude of the conventional indirect cooling completely offsets the TOA warming due to cloud-burning by soot.

Radiative forcings for other scenarios can be calculated from Fig. 5C. For example, if the unpolluted conditions correspond to the baseline haze with a cloud droplet concentration of 100 $\mathrm{cm}^{-3}$ (open circle in Fig. 5C) and the polluted conditions are represented by the INDOEX 1999 haze with a droplet concentration of $250 \mathrm{~cm}^{-3}$ (closed circle), the net forcing due to the aerosol pollution is $+1.7 \mathrm{~W} / \mathrm{m}^{2}$.

However, some of the baseline haze is likely anthropogenic. To roughly assess the anthropogenic aerosol forcings from these simulations, we assume that $70 \%$ of the optical depth in the baseline haze is due to human activities, which implies a clear-sky anthropogenic aerosol forcing for the baseline haze of $-2.7 \mathrm{~W} / \mathrm{m}^{2}$ (35). If we also assume a polluted cloud droplet concentration of $250 \mathrm{~cm}^{-3}$, for the baseline haze the average daytime cloud coverage is 0.11 , which leaves 0.89 of the sky effectively cloud-free. Hence, we can estimate the anthropogenic forcing of the baseline haze under these cloudy conditions to be $\left(-2.7 \mathrm{~W} / \mathrm{m}^{2}\right)(0.89)=-2.4 \mathrm{~W} / \mathrm{m}^{2}$, just more than enough to balance the net forcing in the example from the preceding paragraph $\left(+1.7 \mathrm{~W} / \mathrm{m}^{2}\right)$. With these assumptions the net anthropogenic aerosol forcing is $-0.7 \mathrm{~W} / \mathrm{m}^{2}$, which is well within the noise level of the baseline ensemble. If a smaller fraction of the baseline haze is assumed to be anthropogenic, the net anthropogenic forcing for this scenario can become positive; complete cancellation occurs when half the optical depth in the baseline haze is assumed to be anthropogenic.

At the top of the atmosphere, the net aerosol forcing can be positive, negative, or zero for our simulations, depending on assumptions about unpolluted and polluted conditions. At the ocean surface, the forcings due to direct absorption and scattering by the aerosols reinforce each other (compare the first and second lines of Table 1). Cloud-burning by soot allows more sunlight to reach the surface, which overwhelms the infrared compensation due to reductions in cloud cover. Hence, at a droplet concentration of $250 \mathrm{~cm}^{-3}$, the cloud-burning effect of the 
INDOEX 1998 haze equivalent increases the net radiative flux into the surface relative to the clear-sky forcings by $4.4 \mathrm{~W} / \mathrm{m}^{2}$ (compare the last two columns of the second and third lines in Table 1). This relative increase is too small to completely offset the direct effects at the surface. In addition, we consider the conventional indirect effects, which reinforce the clear-sky total aerosol forcing at the surface. For unpolluted clouds with a droplet concentration of 100 $\mathrm{cm}^{-3}$ and polluted clouds with a droplet concentration of $250 \mathrm{~cm}^{-3}$, the net surface forcing for the INDOEX 1998 haze equivalent is essentially unchanged from its clear-sky value (line 3 of Table 1), implying that the magnitude of the conventional indirect forcing completely offsets the impact of cloud-burning by soot.

We have demonstrated through model simulations (36) that solar absorption by aerosols during the northeast monsoon over the Indian Ocean can reduce daytime cloud coverage by nearly half in a specific case of trade-cumulus. The reduction of cloudiness exerts a positive radiative forcing at the top of the atmosphere that partially offsets the direct aerosol forcing and the conventional indirect forcings (the net forcing depends on meteorological conditions and assumptions about unpolluted and polluted aerosols). However, we cannot also rule out extreme scenarios in which cloud burning completely offsets or even overwhelms the other aerosol forcings, in which case the net anthropogenic forcing by aerosols could be zero or even positive at the top of the atmosphere. We suggest that the pervasive presence of dark hazes contributed to the scarcity of clouds during INDOEX. It is likely that the lack of clouds was largely due to the dryness of air flowing off the Indian subcontinent, and the soot-effect served to diminish cloud cover even further. Note that we have considered only one meteorological scenario in our simulations, and the response of cloudy boundary-layers to aerosol-induced solar heating certainly depends on meteorology ( $(\underline{32})$. We also note that the magnitude of solar heating measured during INDOEX is not specific to that particular time and place; comparable aerosol-induced solar heating rates were measured during a field experiment off the East Coast of the United States during July 1996 (37).

Trade-cumulus have not been the subject of as much attention as some other cloud types, since they do not have as strong a net heating or cooling effect globally as do cirrus and stratocumulus. Beyond any radiative impact, however, is their importance to overall climate dynamics. Trade-cumulus cover vast amounts of the global ocean, and they are part of the feeder system for the deep convection of the tropics. A reduction of the moistening and cooling of the lower troposphere by trade-cumulus may weaken deep convection in the intertropical convergence zone, and potentially alter the tropical Hadley circulation. 


\section{REFERENCES AND NOTES}

1. V. Ramanathan et al., Indian Ocean Experiment (INDOEX), A Multi-Agency Proposal for a Field Experiment in the Indian Ocean $\left(\mathrm{C}^{4}\right.$, Scripps Institution of Oceanography, UCSD, La Jolla, CA, 1996), 83 pp.

2. S. Twomey, Atmos. Environ. 8, 1251 (1974).

3. B. A. Albrecht, Science 245, 1227 (1989).

4 . A. S. Ackerman, O. B. Toon, P. V. Hobbs, Science 262, 226 (1993).

5. R. Pincus, M. B. Baker, Nature 372, 250 (1994).

6. L. F. Radke, J. A. Coakley Jr., M. D. King, Science 246, 1146 (1989).

7. E. E. Hindman, W. M. Porch, J. G. Hudson, P. A. Durkee, Atmos. Environ. 28, 3393 (1994).

8. J. P. Taylor, A. S. Ackerman, Q. J. R. Meteorol. Soc. 125, 2643 (1999).

9. A. Jayaraman et al., J. Geophys. Res. 103, 13827 (1998).

10. S. K. Satheesh and V. Ramanathan [in press at Nature] report direct radiometric observations at the surface and top-of-atmosphere over Kaashidhoo, a Maldivian island in the Indian Ocean, obtained during February and March 1998. According to their observations, the diurnal-average aerosol-induced solar absorption was $\sim 9 \mathrm{~W} / \mathrm{m}^{2}$ for an average aerosol optical depth of 0.2 (at 0.5 $\mu \mathrm{m})$. They also report a range of $0.88-0.90$ for measurements of the aerosol single-scattering albedo at $0.5 \mu \mathrm{m}$ (which take into account the effects of relative humidity on particle size). 11. Satellite retrievals of monthly diurnal-average low-cloud fractional coverage during February 1989-1993 range from $\sim 0.2-0.3$ at the equator to $\sim 0.1-0.2$ at $10^{\circ} \mathrm{N}$ [W. B. Rossow, R. A. Schiffer, Bull. Amer. Meteor. Soc., 72, 2 (1991)]. METEOSAT-5 retrievals by VR yield comparable values for 1999.

12. A. S. Ackerman, O. B. Toon [Nature 380, 512 (1996)] artificially increased the solar heating within cloud droplets to explore the implications of enhanced solar absorption by clouds (as reported by references therein). The additional solar absorption required to match the observed enhancement at noon was $125 \mathrm{~W} / \mathrm{m}^{2}$, equivalent to a diurnal average of $\sim 50 \mathrm{~W} / \mathrm{m}^{2}$. 13. M. C. Wyant, C. S. Bretherton, H. A. Rand, D. E. Stevens, J. Atmos. Sci. 54, 168 (1997). 14. B. A. Albrecht, J. Atmos. Sci. 38, 97 (1981).

15. B. Stevens et al., paper presented at 13th American Meteorological Society Conference on Boundary Layers and Turbulence, Dallas, TX, January 1999. The simulations here are derived from a model intercomparison setup described therein. 
16. K. Brill, B. Albrecht, Mon. Wea. Rev. 110, 601 (1982).

17. The dynamics model [D. E. Stevens, C. S. Bretherton, J. Comput. Phys. 129, 284 (1997)]

solves the anelastic Navier-Stokes equations in conservative form using $5 \mathrm{~s}$ time steps on a domain spanning $6.4 \times 6.4 \mathrm{~km}$ horizontally and $3 \mathrm{~km}$ vertically, which is uniformly discretized into $32 \times 32 \times 75$ grid cells. The boundary conditions are doubly periodic in the horizontal, and rigid at the top and bottom. Surface fluxes are parameterized through similarity relations [J. A. Businger, J. C. Wyngaard, Y. Izumi, E. F. Bradley, J. Atmos. Sci. 28, 181 (1971)]. A sponge layer at the top of the model dampens trapped buoyancy waves at altitudes $>500 \mathrm{~m}$ above the trade inversion, which is defined as the horizontal-average height where the total water mixing ratio is $6.5 \mathrm{~g} / \mathrm{kg}$. First-order turbulence closure is used for subgrid-scale mixing [J. Smagorinsky, Mon. Wea. Rev. 91, 99 (1963); D. K. Lilly, Tellus 14, 1012 (1962)] with a stability-dependent mixing length [J .W. Deardorff, Bound. Layer Meteor. 18, 495 (1980)] modified to account for the effects of evaporation [P. J. Mason, M. K. MacVean, J. Atmos. Sci. 47, 1012 (1990)]. Large-scale subsidence is calculated as the product of the divergence rate (assumed constant) and altitude. Subsidence and radiative forcings are linearly attenuated to zero in the $300 \mathrm{~m}$ above the trade inversion to prevent drift of the overlying atmospheric properties due to any imbalanced forcings.

18. Radiative transfer is calculated for each column every 2.5 minutes using a two-stream model [O. B. Toon, C. P. McKay, K. Santhanam, J. Geophys. Res. 94, 16287 (1989)] in which water vapor continuum absorption has been modified [S. A. Clough, F. X. Kniezys, R. W. Davies, Atmos. Res. 23, 229 (1989)]. Cloud water from the dynamics model is fit to a log-normal droplet size distribution with a prescribed number concentration and a geometric SD of 1.5. Aerosol and cloud optical properties are computed through Mie calculations [O. B. Toon, T. P. Ackerman, Appl. Opt. 20, 3657 (1981)] using the complex index of refraction for liquid water compiled by A. S. Ackerman, O. B. Toon, P. V. Hobbs [J. Atmos. Sci. 52, 1204 (1995)]. We specify an overlying water vapor column of $1 \mathrm{~g} / \mathrm{cm}^{2}$; the ocean surface albedo is assumed to be independent of wavelength and is determined from the wind speed at $10 \mathrm{~m}$ (averaging $\sim 8 \mathrm{~m} / \mathrm{s}$ ) and the solar zenith angle using the parameterization of J. Hansen et al. [Mon. Wea. Rev. 111, 609 (1983)]. 19. E. Augstein, H. Riehl, F. Ostapoff, V. Wagner, Mon. Wea. Rev. 101, 101 (1973). 20. We generally follow $(\underline{15})$ for surface properties and initial soundings, which are based on the measurements and average position of the upstream ship (the Planet): sea-surface temperature fixed at $298 \mathrm{~K}(\underline{16})$, surface pressure fixed at $1015 \mathrm{mb}(\underline{10})$, latitude fixed at $15^{\circ} \mathrm{N}$, geostrophic 
(and initial) winds from Fig. 4 of (19), and soundings of temperature and water vapor mixing ratio averaged by Bruce Albrecht to preserve the jumps at the base and top of the transition layer. The large-scale divergence rate is fixed at $4.2 \cdot 10^{-6} \mathrm{~s}^{-1}$, the mean value derived from the observations (16). Pseudo-random perturbations of temperature and water vapor mixing ratio are imposed below the inversion to promote turbulence initially; the amplitudes of the perturbations (which horizontally average to zero) are $0.1 \mathrm{~K}$ and $0.025 \mathrm{~g} / \mathrm{kg}$, respectively $(\underline{15})$.

21 . We justify our assumption of a fixed sea-surface temperature on the basis that its diurnal range is negligible: for our simulations (with maximum insolation of $950 \mathrm{~W} / \mathrm{m}^{2}$, an average precipitation rate of $\sim 0.1 \mathrm{~mm} / \mathrm{d}$, and $10-\mathrm{m}$ wind speed of $\sim 8 \mathrm{~m} / \mathrm{s}$ ) the parameterization of P. J. Webster, C. A. Clayson, J. A. Curry [J. Clim. 9, 1712, (1996)] yields an amplitude of only $0.2 \mathrm{~K}$ for the diurnal variation in sea-surface temperature.

22. Advective fluxes for the ATEX triangle were calculated by (19), from which advective forcings can be computed (as small differences between large terms): in the lower $60 \mathrm{mb}$ of the atmosphere, a drying tendency of $1.4 \mathrm{~g} / \mathrm{kg} / \mathrm{d}$ and a cooling tendency of $0.9 \mathrm{~K} / \mathrm{d}$ are indicated. Following $(\underline{15})$, we parameterize these forcings to fade linearly from a maximum at the surface to zero at the trade inversion. The surface drying tendency we use $(1.5 \mathrm{~g} / \mathrm{kg} / \mathrm{d})$ is taken directly from $(\underline{15})$. We double the surface cooling tendency of $(\underline{15})$ to $2 \mathrm{~K} / \mathrm{d}$, which compensates for a diurnal-average clear-sky cooling rate $(1.7 \mathrm{~K} / \mathrm{d}$ infrared cooling, $0.7 \mathrm{~K} / \mathrm{d}$ solar heating) that is half the value imposed in (15).

23. In the real atmosphere changes in aerosol-induced heating rates (tending to decrease cloud coverage) are linked to changes in cloud droplet concentrations (tending to increase cloud coverage) through microphysical details of the aerosol population (specifically, their chemical composition and size distribution). Any net effect of these opposed tendencies depends on such microphysical details, as well as the meteorology. Rather than attempt to comprehensively evaluate any net effects, we instead decouple the forcings by varying the haze properties and cloud droplet concentrations separately.

24 . The model domain is initially cloudless; the cited droplet concentrations apply only to grid cells in which clouds appear. In all simulations the number concentration of haze particles increases linearly from zero at the ocean surface up to $600 \mathrm{~m}$, maintains a uniform value up to the trade inversion, and vanishes linearly in the overlying $300 \mathrm{~m}$. The haze particle size distribution is log-normal with a geometric mean radius of $0.1 \mu \mathrm{m}$ and a geometric SD of 1.8. 25 . For clear-sky conditions at $5^{\circ} \mathrm{N}$ on March 1, a 1.8-km deep layer of our idealized INDOEX 1998 haze absorbs $7.4 \mathrm{~W} / \mathrm{m}^{2}$ of solar radiation (diurnally averaged), which is comparable to the 
absorption measured during INDOEX 1998 (10). Optical properties of black carbon (soot) are taken from [P. Chylek, V. Ramaswamy, R. J. Cheng, J. Atmos. Sci. 41, 3076 (1984)].

26 . To address the sensitivity of the simulations to small variations in initial conditions, for the baseline we run an ensemble of four simulations that differ only in the pseudo-random distribution of initial perturbations of temperature and water vapor. Output from one member of the ensemble is shown in Figs. 2 and 3.

27 . Vertically resolved cloud fraction, defined as the fraction of cells in each layer with cloud water $>0.05 \mathrm{~g} / \mathrm{kg}$, is distinct from the fractional cloud coverage we define subsequently, which is evaluated from vertically integrated columns.

28. During the first five days of ATEX (the observation period upon which our meteorology is based) surface reports of the cloud fractional coverage (which may include clouds above the boundary layer) ranged from an early morning maximum $\sim 0.9$ on two days to a minimum of $\sim 0.2$ one afternoon; the average value over the period was 0.5 [B. Albrecht, J. Atmos. Sci. 48, 1519 (1991)]. For comparison, the simulated cloud coverage depends on a number of factors, including the criterion used to count cloudy grid columns, the model resolution, subgrid-scale mixing assumptions, and the water vapor above the inversion. With our model setup, the diurnal average (0.23) and range (0.1-0.4) from the baseline simulations are more comparable to those found over the Indian Ocean during the northeast monsoon (11).

29. We assume that all the enhanced solar absorption occurs only within the haze, though some fraction of the soot is likely to be incorporated into cloud droplets through nucleation and coagulation/coalescence. Cloud droplets (of typical radius $10 \mu \mathrm{m}$ ) collect significantly more sunlight than do haze (of typical radius $0.1 \mu \mathrm{m}$ ), and hence a fixed amount of soot will absorb more sunlight when embedded within cloud droplets (particularly when most of the haze lies below the bulk of cloud cover); such an effect could be expected to increase the impact of the soot on boundary-layer dynamics. Yet this expectation is not borne out by simulations in which all the soot is assumed to be within cloud droplets (when present within a grid cell) because such a small volume of boundary-layer air is occupied by cloud in our simulations.

30. The reductions in cloud coverage due to solar absorption in the INDOEX hazes are not completely independent of droplet concentration. The strong increase in daytime cloud coverage between droplet concentrations of 50 and $1.00 \mathrm{~cm}^{-3}$ only for the simulations without soot implies that the effect of soot on cloud cover is maximum at a droplet concentration of $100 \mathrm{~cm}^{-3}$. However, the departure of that maximum from the average cloud-burning effect is not significant 
compared to the noise found for the baseline ensemble.

31. As seen in Fig. 5B, the average liquid water path is roughly independent of droplet concentration for any particular aerosol. The increases of cloud coverage with droplet concentration in these simulations (Fig. 5A) are largely due to enhancement of total droplet cross-sectional area and therefore optical depth (which vary as the cube root of droplet concentration, holding liquid water path fixed). Because cloud coverage is defined as the fraction of columns exceeding an optical depth threshold (2.5), columns do not need as much liquid water path at increased droplet concentrations to be counted as cloudy.

32. Simulations with moisture enhanced above the inversion layer (at $6 \mathrm{~g} / \mathrm{kg}$, up from $4.5 \mathrm{~g} / \mathrm{kg}$ used in our other simulations) produce moister clouds with greater fractional coverage that are more strongly influenced by both the soot cloud-burning and the conventional indirect aerosol effects.

33. An increase in cloud coverage results in more solar energy being reflected (a cooling effect), while at the same time allowing less infrared energy to escape to space (a warming effect). The solar forcing dominates any infrared compensation in trade cumulus, which therefore exert a net cooling influence (compare clear-sky to cloudy net fluxes in Fig. 5C).

34. J. T. Houghton et al., Climate Change 1995: The Science of Climate Change (Cambridge University Press, Cambridge, UK, 1996), pp. 112-117.

35. S. K. Satheesh et al. [J. Geophys. Res. 104, 27421 (1999)] estimate that $60 \%$ of the aerosol optical depth in the INDOEX 1998 haze was anthropogenic. Applying this estimate to the average $0.5-\mu \mathrm{m}$ optical depth they measured $(0.20)$, the implied anthropogenic aerosol optical depth is 0.12 , which is $70 \%$ of the aerosol optical depth for our baseline haze.

36. The scope of our calculations ( 17 simulations of $30 \mathrm{~h}$ ) demand a number of computational efficiencies, which include parameterized cloud microphysics, moderate grid resolution and domain area, and no treatment of horizontal radiative transfer.

37. Distributed over a $2.5 \mathrm{~km}$ deep boundary layer (not in a trade cumulus regime), the diurnal-average aerosol forcings reported by P. B. Russel et al. [J. Geophys. Res. 104, 2289] and P. Hignett, J. P. Taylor, P. N. Francis, M. D. Glew [J. Geophys. Res. 104, 2289, 2279] yield clear sky heating rates of 0.5 and $0.6 \mathrm{~K} / \mathrm{d}$, respectively. In comparison, the diurnal-average aerosol-induced heating rates in the boundary layer range from $0.5-1 \mathrm{~K} / \mathrm{d}$ for our idealized INDOEX hazes.

38. This work was supported by the National Aeronautics and Space Administration (NASA grants NAG5-6504 and NAG5-8362), the U.S. Department of Energy, and the National Science 
Foundation. The Micro Pulse Lidar measurements were supported by NASA contract NA55-31363 and the NASA SIMBIOS project. We thank Jim Coakley for performing radiative transfer calculations to compare against ours, and Cindy Twohy for helpful discussions regarding droplet nuclei measurements from INDOEX, the National Oceanic and Atmospheric Administration (NOAA) Pacific Marine Environmental Laboratory (PMEL) and the crews of the R/V Ronald H. Brown and the National Center for Atmospheric Research (NCAR) C-130 for making the INDOEX measurements possible, and two anonymous reviewers for comments that improved the manuscript. 
Table 1. Diurnal-average radiative forcings $\left(\mathrm{W} / \mathrm{m}^{2}\right)$, computed as differences in net radiative fluxes (shown in Fig. $5 \mathrm{C}$ for TOA) between model simulations with progressively increasing differences between aerosols.

\begin{tabular}{llcccccc}
\hline \multicolumn{1}{c}{ Aerosol forcing } & Aerosols (see text) & $\begin{array}{c}\text { Cloud droplet } \\
\text { concentrations } \\
\left(\mathrm{cm}^{-3}\right)\end{array}$ & $\begin{array}{c}\text { Clear } \\
\text { sky }\end{array}$ & $\begin{array}{c}\text { Cloudy } \\
\text { sky }\end{array}$ & $\begin{array}{c}\text { Clear } \\
\text { sky }\end{array}$ & $\begin{array}{c}\text { Cloudy } \\
\text { sky }\end{array}$ \\
\cline { 5 - 8 } & Baseline $\rightarrow$ INDOEX 1998 & 250 & +0.4 & +3.7 & -7.2 & -2.8 \\
\hline $\begin{array}{l}\text { Absorption } \\
\text { Absorption and scattering }\end{array}$ & INDOEX 1998 $\rightarrow 1999$ & 250 & -3.4 & +0.7 & -10.3 & -5.9 \\
$\begin{array}{c}\text { Absorption, scattering, and } \\
\text { conventional indirect }\end{array}$ & INDOEX 1998 $\rightarrow$ 1999 & $100 \rightarrow 250$ & -3.4 & -3.9 & -10.3 & -10.4 \\
\hline
\end{tabular}

${ }^{*}$ About $20 \%$ of aerosol volume in the baseline haze is replaced by soot in the INDOEX 1998 haze. This change of composition not only results in solar absorption but also enhances scattering in the haze. However, the radiative impact of increasing the absorption optical depth from 0.0 to 0.2 far exceeds that due to increasing the scattering optical depth from 0.17 to 0.18 . 


\section{FIGURE CAPTIONS}

Fig. 1. Images of clouds within clean and dirty marine boundary layers obtained during the INDOEX Intensive Field Phase in 1999. Photographs taken by AJH from the NCAR C-130 on February 20 at (A) $4.3^{\circ} \mathrm{S}, 73^{\circ} \mathrm{E}$ (in clean air from the southern Indian Ocean) and (B) $0.2^{\circ} \mathrm{N}$, $73^{\circ} \mathrm{E}$ (in polluted air $1000 \mathrm{~km}$ distant from India). Time-height contours of particle backscatter cross-section (in units of $\mathrm{km}^{-1} \mathrm{sr}^{-1}$ ) measured by Micro Pulse Lidar (MPL) from the NOAA R/V Ronald H. Brown (operated by EJW and Piotr J. Flatau) on (C) February 25 steaming from $7^{\circ} \mathrm{S}$, $61^{\circ} \mathrm{E}$ to $6^{\circ} \mathrm{S}, 62^{\circ} \mathrm{E}$ (in clean air from the southern Indian Ocean) and (D) March 7 from $11^{\circ} \mathrm{N}$, $68^{\circ} \mathrm{E}$ to $12^{\circ} \mathrm{N}, 68^{\circ} \mathrm{E}$ (in polluted air $1000 \mathrm{~km}$ distant from India). The marine boundary layer in (D) is overlain by a residual continental boundary layer (between $\sim 1.5$ and $3.5 \mathrm{~km}$ altitude) advecting pollution directly from India, as shown by back-trajectories (R. R. Draxler and G. D. Hess, NOAA Tech Memo ERL ARL-224, 24 pp., 1997) and discussed further by S. Raman, D. S. Niyogi, O. Roswintiarti [submitted to Bound. Layer Meteor.]. The MPL operates at a wavelength of $0.523 \mu \mathrm{m}$; the signal processing is described by E. J. Welton et al. [in press at Tellus B]. White regions in (C) and (D) are clouds.

Fig. 2. Evolution of horizontal averages of (A) liquid water mixing ratio in cloud (grid cells with $>0.05 \mathrm{~g} / \mathrm{kg}$ liquid water) and (B) relative humidity in a baseline simulation. The profiles are output every 5 minutes.

Fig. 3. Snapshots of the model domain taken during the early $(6 \mathrm{~h} 7 \mathrm{~m})$ and mature $(6 \mathrm{~h} 37 \mathrm{~m})$ growth stages of a convective episode. Plotted is the isosurface of $0.05 \mathrm{~g} / \mathrm{kg}$ liquid water mixing ratio. Note that the vertical scale $(2 \mathrm{~km})$ is stretched relative to the horizontal $(6.4 \times 6.4 \mathrm{~km})$.

Fractional cloud coverage (defined as in $(\underline{13})$ by the fraction of columns with optical depth $>2.5$ ) is 0.1 at $6 \mathrm{~h} 7 \mathrm{~m}$ and 0.3 at $6 \mathrm{~h} 37 \mathrm{~m}$.

Fig. 4. Evolution of domain averages of (A) fractional cloud coverage (as defined in Fig. 3), (B) liquid water path (column of cloud water, in units of $\mathrm{g} / \mathrm{m}^{2}$ ), and (C) altitude of the trade inversion (mean height of the $6.5 \mathrm{~g} / \mathrm{kg}$ total water mixing ratio surface, in units of $\mathrm{m}$ ). Note that the liquid water path in (B) is averaged over clear and cloudy air; the average liquid water path in cloudy columns is greater by a factor inverse of the fractional cloud coverage in (A). Results are shown as centered 6-h running averages to smooth over the convective noise seen in Fig. 2.

Cloud droplet concentrations are fixed at $250 \mathrm{~cm}^{-3}$ for the simulations shown. For the baseline (grey area) the haze is non-absorbing and the concentration is $1200 \mathrm{~cm}^{-3}$; for the INDOEX 1998 
and 1999 cases (dotted and dashed lines) the haze absorbs solar radiation (as described in the text) and the concentrations are 1200 and $2400 \mathrm{~cm}^{-3}$, respectively. For the modified baseline (solid line), solar radiation is omitted. For the baseline an ensemble of four simulations was run $(\underline{27})$; the grey area represents the range of values (after applying running averages) realized in the ensemble.

Fig. 5. Domain averages of (A) daytime fractional cloud coverage (as in Fig. 4, averaged between 8-16 h, during which $90 \%$ of solar energy is incident), (B) daytime liquid water path (as in Fig. 4), and (C) diurnal-average net radiative flux (in units of $\mathrm{W} / \mathrm{m}^{2}$ ) at the top-of-atmosphere. Diurnal averages are computed by averaging between $6-30 \mathrm{~h}$, thereby skipping over the first $6 \mathrm{~h}$ of model spin-up. The net radiative fluxes for cloudless conditions are shown at a droplet concentration of zero. Variations with droplet concentrations (in units $\mathrm{of}^{-3}$ ) are shown for simulations in which the haze is non-absorbing (solid line labeled "No soot"), and for the idealized 1998 and 1998 INDOEX hazes (described in the text). The solid lines are drawn through the median values of the baseline ensemble; the error bars represent the ranges of ensemble values. Illustrative unpolluted and polluted conditions (discussed in the text) are shown as open and solid circles. 

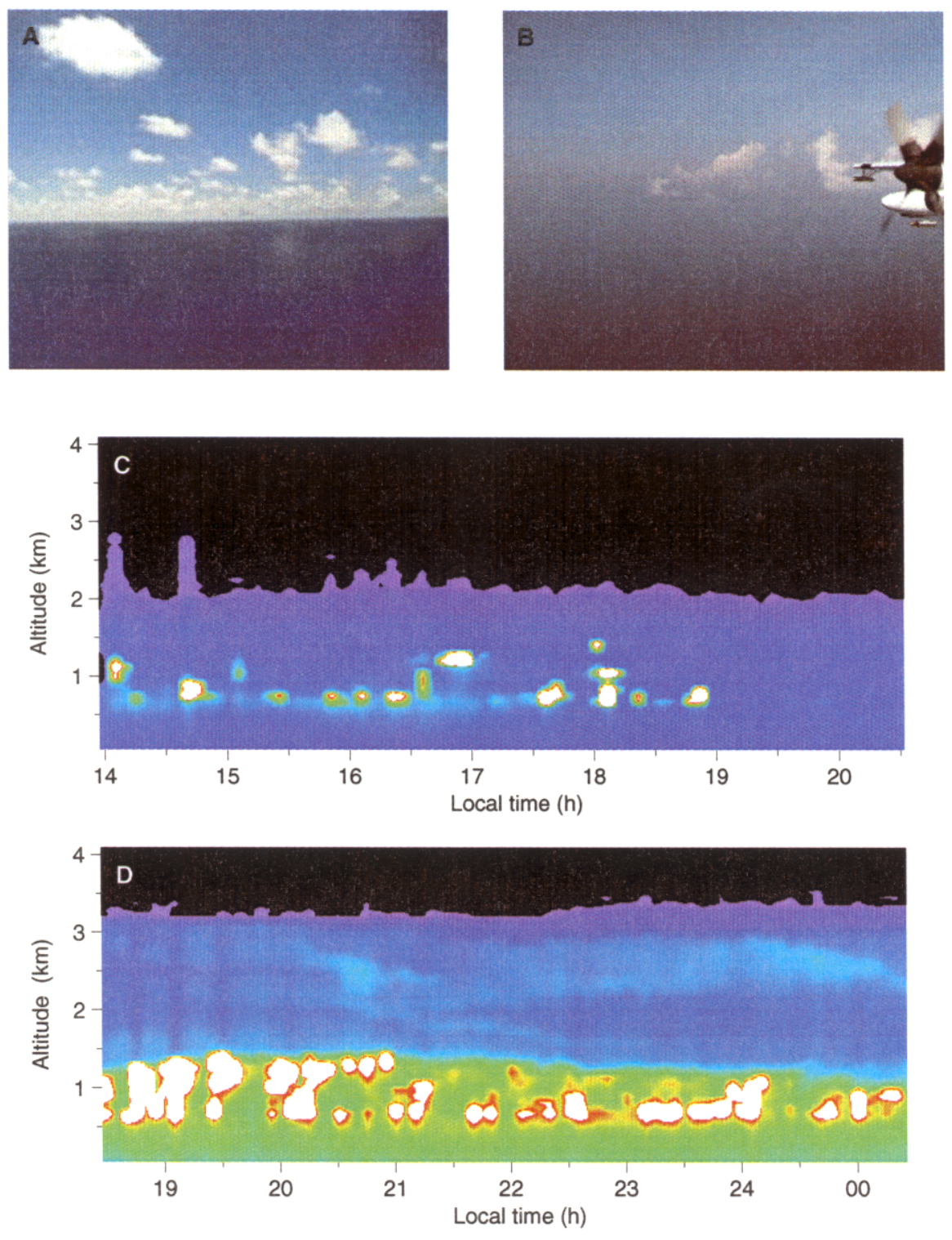

$\begin{array}{lllll}0.000 & 0.002 & 0.005 & 0.007 & 0.010\end{array}$

Backscatter cross-section $1 /(\mathrm{km} \mathrm{sr})$ 

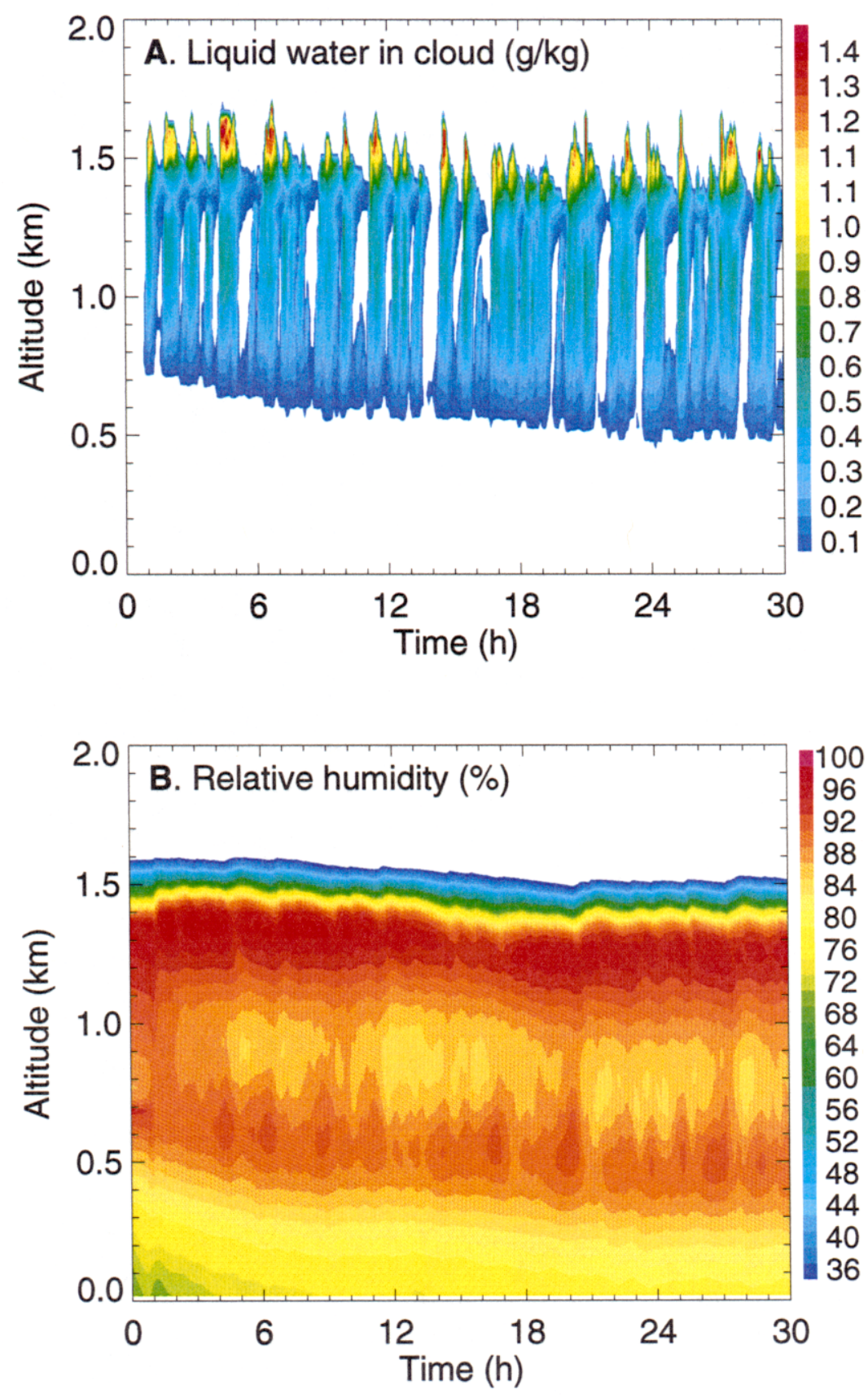

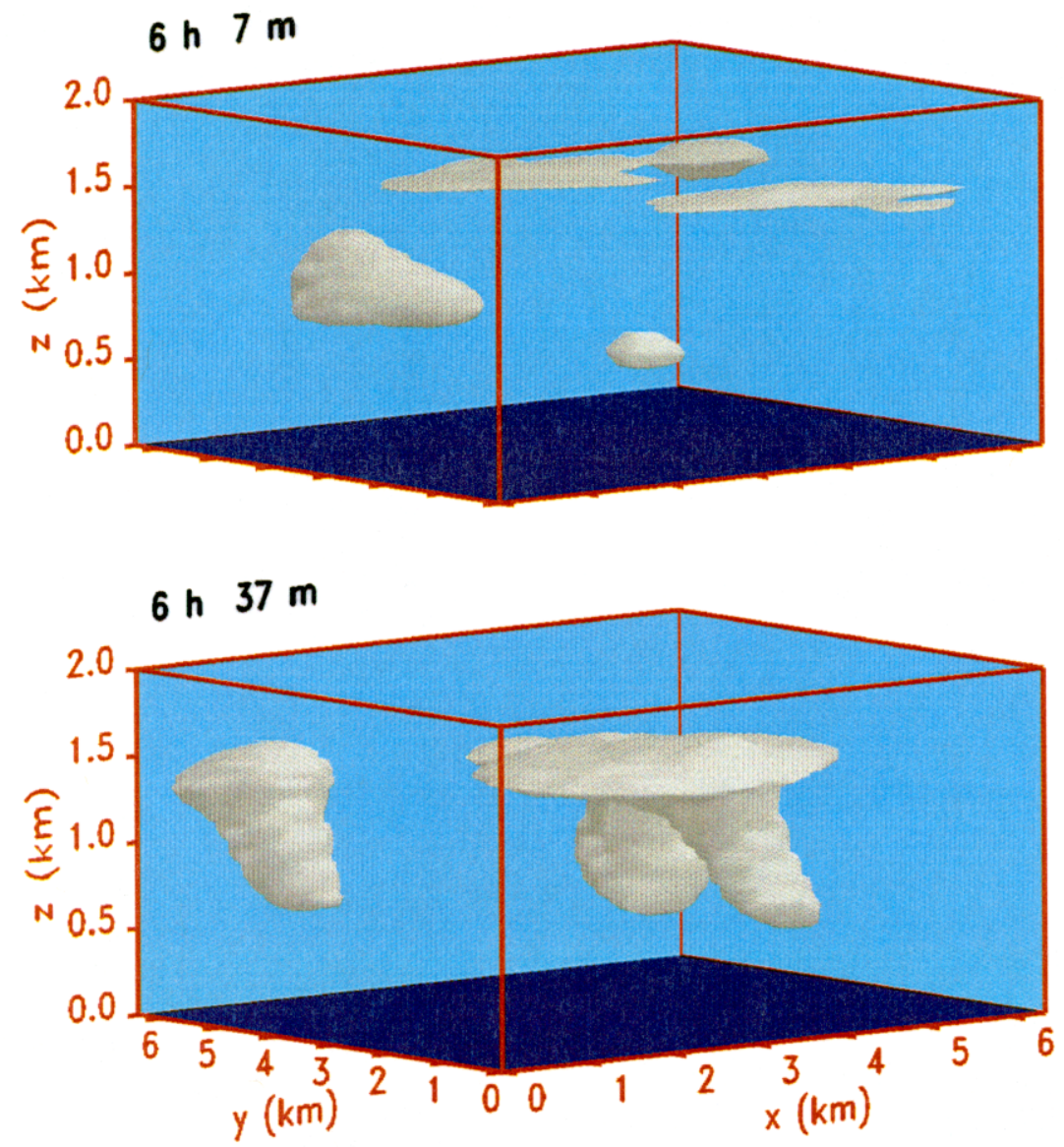

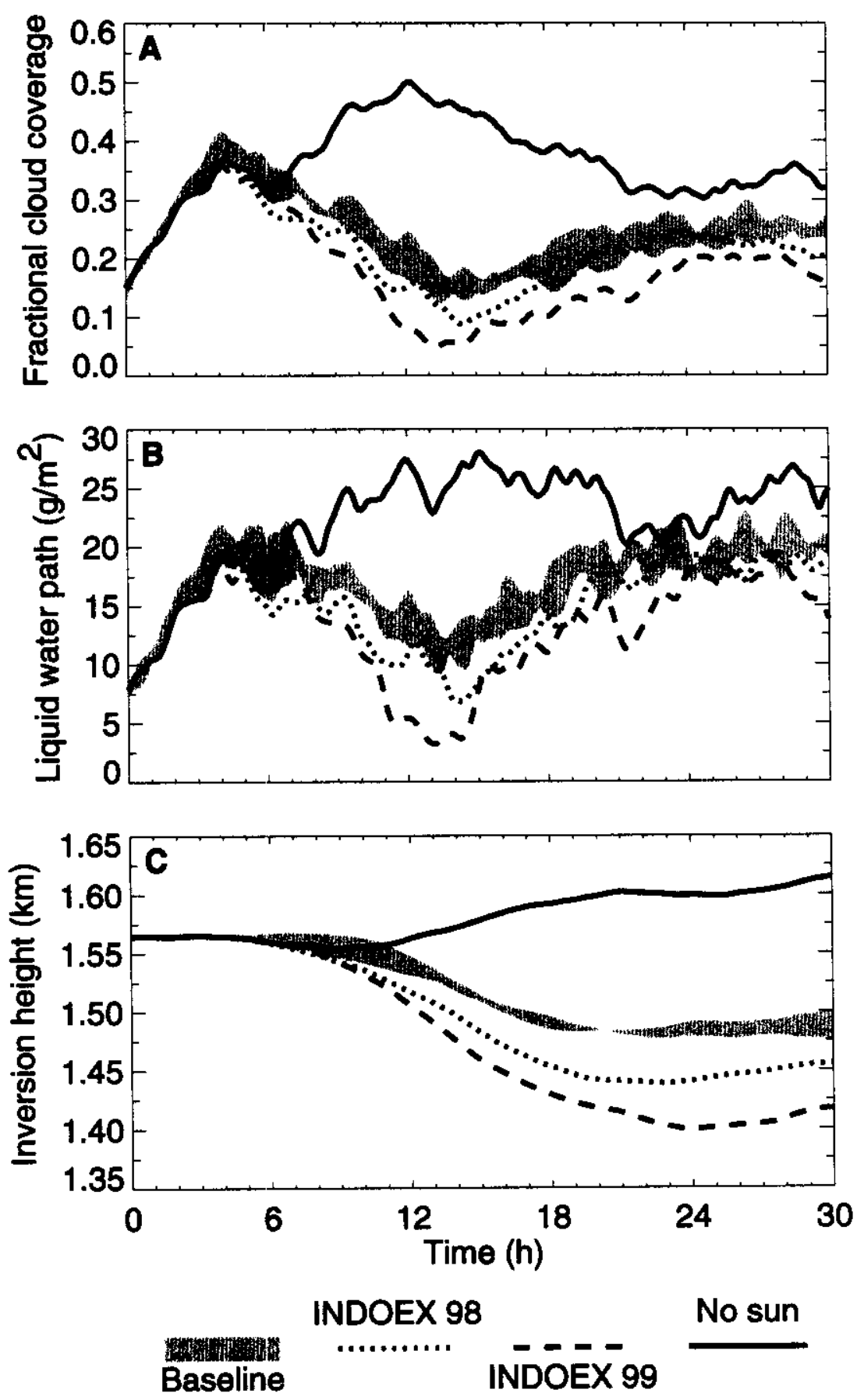

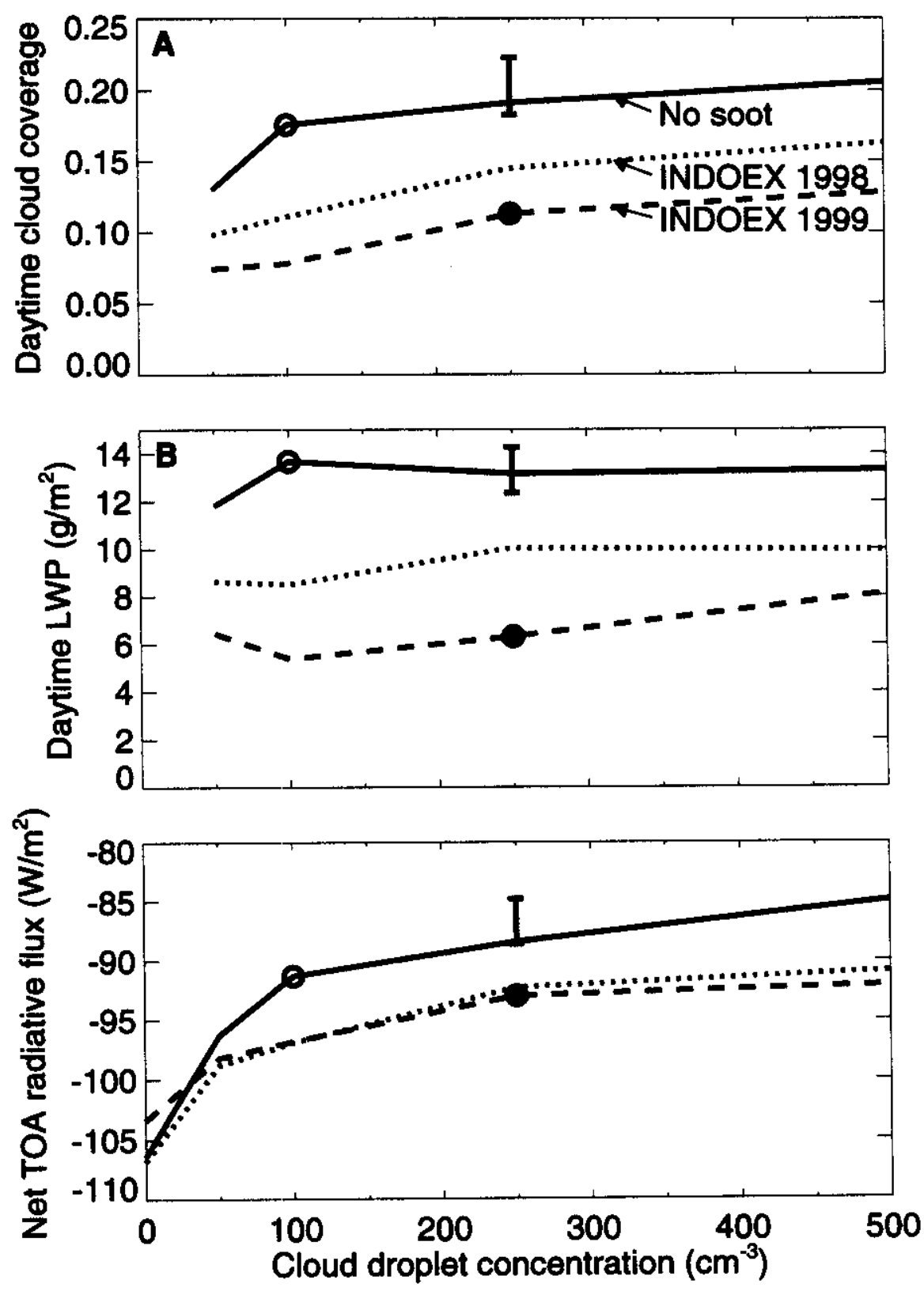